\title{
Climatology of ionospheric slab thickness
}

\author{
B. Jayachandran ${ }^{1}$, T. N. Krishnankutty ${ }^{2}$, and T. L. Gulyaeva ${ }^{3,4}$ \\ ${ }^{1}$ Sree Narayana College, Varkala, Trivandrum, Kerala, 695145, India \\ ${ }^{2}$ Sree Narayana College, Kollam, Kerala, 691001, India \\ ${ }^{3}$ IZMIRAN, 142190 Troitsk, Moscow Region, Russia \\ ${ }^{4}$ Space Research Centre, PAS, Bartycka, 18A, Warsaw, Poland
}

Received: 10 July 2002 - Revised: 8 April 2003 - Accepted: 20 May 2003 - Published: 1 January 2004

\begin{abstract}
The ionospheric slab thickness $\tau$ defined as a ratio of the total electron content (TEC) to the F-region peak electron density $(\mathrm{Nm} \mathrm{F} 2)$ has been analysed during the solar maximum (1981) and minimum (1985) phases of an intense, the 21st, solar cycle. Hourly values of TEC and NmF2 collected at Hawaii (low-latitude), Boulder (mid-latitude) and Goosebay (high-latitude) are used in the study. Climatology of the slab thickness is described by the diurnal, seasonal, solar and magnetic activity variations of $\tau$ for the different latitude zones. It is found that, for magnetically quiet days of solar maximum, increased ionization of $\mathrm{Nm} \mathrm{F} 2$ and TEC during the daytime is accompanied by an increased thickness of the ionosphere compared to the night-time for non-auroral latitudes. However, the reverse is found to be true during the solar minimum compensating TEC against a weak nighttime ionization of $N m \mathrm{~F} 2$. For the high-latitude the night-time slab thickness is higher compared to the daytime for both the solar phases. Ratios of daily peak to minimum values of slab thickness vary from 1.3 to 3.75 with the peaks of $\tau$ often observed at pre-sunrise and post-sunset hours. The average night-to-day ratios of $\tau$ vary from 0.68 to 2.23 . The day-today variability of $\tau$, expressed in percentage standard deviation, varies from $10 \%$ by day (equinox, high-latitude) to $67 \%$ by night (summer, mid-latitude) during solar minimum and from $10 \%$ by day (winter and equinox, mid-latitude) to $56 \%$ by night (equinox, high-latitude) during solar maximum. A comprehensive review of slab thickness related literature is given in the paper.
\end{abstract}

Key words. Ionospheric physics

\section{Introduction}

The ionospheric slab thickness is defined as the ratio of the total electron content (TEC) to the F-region peak electron density $(\mathrm{Nm} \mathrm{F} 2)$. It represents the equivalent thickness

Correspondence to: T. L. Gulyaeva

(tamara@izmiran.troitsk.ru) of the ionosphere having a constant uniform density equal to that of the F2 peak. It is capable of addressing many ionospheric phenomena and has been studied over the last five decades (e.g. Bhonsle et al., 1965; Kersley and Hajeb Hosseinieh, 1976; Huang, 1983; Bhuyan and Tyagi, 1985; Davies and Liu, 1991; Minakoshi and Nishimuta, 1994; Gulyaeva, 1997). The $\tau$ parameter has renewed popularity by virtue of abandant TEC monitoring by GPS satellites. A study of this parameter at any location provides information about the nature of the distribution of ionization at that location. Besides, from the point of view of satellite to ground radio communication, the equivalent slab thickness is a very useful parameter since it contains all the new information obtainable from TEC measurements, which is not readily available in $f o \mathrm{~F} 2$ (Titheridge, 1973). For an $\alpha-$ Chapman layer, the value of $\tau$ is shown to be equal to $4.13 \mathrm{H}$, where $H$ is the scale height of the ionosphere (Wright, 1960). Titheridge (1973) has developed a relationship between $\tau$ and neutral temperature. Furman and Prasad (1973) found that $\tau$ in general depends upon the plasma scale height but is not a good indicator of either electron or ion temperature.

Slab thickness is a significant parameter since it contains information regarding the neutral temperature and, for an assumed electron density profile, it can be related directly to the scale height of the ionizable constituents. Though primarily a measure of the neutral gas temperature, it is modified by ion composition and changes in the upper atmosphere. A number of studies have been reported on the variation of this parameter under different geophysical conditions. Detailed investigation of this parameter for low-latitudes (e.g. Bhuyan et al., 1986; Rao et al., 1988; Davies and Liu, 1991) and midlatitudes (e.g. Bhonsle et al., 1965; Titheridge, 1973; McNamara and Smith, 1982; Gulyaeva, 1997) are available in the literature. However, studies related to the high-latitude variations of $\tau$ are rather rare (e.g. Buonsanto et al., 1979).

Occurrence of a pre-sunrise peak in $\tau$ has been reported by many investigators for low-latitudes (Walker and Ting, 1972; Bhuyan et al., 1986; Rao et al., 1988) and midlatitudes (Bhonsle et al., 1965; Noxon and Johanson, 1970; 



Fig. 1. Variation of total electron content, the F2-layer critical frequency and slab thickness during 5 quiet days (circles) and 5 disturbed days (crosses) of March 1981 at Goosebay.
Tiltheridge, 1973; Essex 1978; Buansanto et al., 1979; McNamara and Smith, 1982). Minakoshi and Nishimuta (1994) report that for Japanese low and mid-latitudes, a large peak in slab thickness appears during the solar minimum and disappears as the sunspot number ascends; this peak starts to reappear during the solar maximum, particularly during the winter season. A number of theories have been put forward to explain the widely observed feature of predawn peaks in the slab thickness at low and mid-latitudes. Titheridge (1973) explains the presunrise peak in $\tau$ as due to the downward movement of the ionosphere when the neutral winds that have been maintaining the ionosphere decrease or reverse. The early morning peaks in $\tau$ may also appear due to the fact that sunrise is earlier at heights above the F2-layer causing some production at the topside, tending to give TEC a lead over $N m \mathrm{~F} 2$ which is still decaying.

Rastogi (1988) explains the occurrence of presunrise peak $\tau$ values as due to the collapse of the bottom side of the Flayer. The whole phenomenon is suggested to be primarily due to the electrodynamics of the equatorial F-region during the presunrise hours. Furthermore, it is known that the shape factor is most sensitive to the variations of $\mathrm{H}^{+} / \mathrm{O}^{+}$ratio at the $\mathrm{F} 2$ peak or equivalent to the transition level at which $\left[\mathrm{O}^{+}\right]=\left[\mathrm{H}^{+}\right]$(Davies et al., 1976). Large downward fluxes of $\mathrm{H}^{+}$at presunrise hours can decrease the $\mathrm{O}^{+}$to $\mathrm{H}^{+}$transition levels in winter, thereby increasing the topside content and hence the slab thickness. Evans and Holt (1978) measured such fluxes and this would explain the presunrise peak in slab thickness in the winter season; they also report that, in the winter hemisphere, the field aligned plasma flow is from the protonosphere to ionosphere, particularly during the post midnight hours and the duration of this flow is found to be decreasing with increase of solar activity.

The postsunset increase in the $\tau$ values observed during the different seasons under varying solar activity conditions for low-latitude (Bhuyan et al., 1986) could be explained as being due to the secondary fountain effect caused by the postsunset occurrence of a strong eastward electric field existing over the equatorial latitudes (Modi and Iyer, 1989; Balan and Bailey, 1995). The postsunset enhancement in the $\tau$ values observed for the mid-latitude (Minakoshi and Nishimuta, 1994) may also be associated with the night-time enhancements in TEC at mid-latitudes which is primarily due to the field aligned plasma flow from the protonosphere to the ionosphere.

Most of the earlier studies of the ionosphere slab thickness are confined to single station observation under limited solar activity variations. From these studies, it has been found that $\tau$ shows appreciable diurnal, day-to-day, seasonal, solar and magnetic activity variations with considerable dependence on the location of the observing station. The present study is an attempt to investigate the simultaneous variations of $\tau$ for low, mid and high-latitudes, respectively represented by the stations of Hawaii $\left(19^{\circ} \mathrm{N}, 206^{\circ} \mathrm{E}\right)$, Boulder $\left(40^{\circ} \mathrm{N}\right.$, $\left.255^{\circ} \mathrm{E}\right)$ and Goosebay $\left(53^{\circ} \mathrm{N}, 299^{\circ} \mathrm{E}\right)$ during the solar maximum (1981) and minimum (1985) phases of an intense solar cycle. Total electron content (TEC) and the F2-layer peak electron density $(N m \mathrm{~F} 2)$ data, simultaneously collected at the three stations are used for the study. The results presented here are to be viewed against the fact that the three stations in the low, mid and high-latitudes lie in a wide longitude zone of $250 \pm 50^{\circ} \mathrm{E}$. 
Table 1. Satellites used with their sub-ionospheric co-ordinates.

\begin{tabular}{|c|c|c|c|c|c|}
\hline \multirow[t]{3}{*}{ Station } & \multicolumn{2}{|c|}{ Satellites used } & \multicolumn{3}{|c|}{ Sub-ionospheric co-ordinates } \\
\hline & \multirow{2}{*}{1981} & \multirow{2}{*}{1985} & \multirow{2}{*}{$\begin{array}{c}\text { Geomagnetic } \\
\text { Lat. }^{\circ} \mathrm{N}\end{array}$} & \multicolumn{2}{|c|}{ Geographic } \\
\hline & & & & Lat. $^{\circ} \mathrm{N}$ & Long. ${ }^{\circ} \mathrm{E}$ \\
\hline Hawa & GOES-3 & GOES-3 & 19. & 19 & 206 \\
\hline Boulder & GOES-3 & GOES-3 & 48.9 & 40 & 255 \\
\hline Goosebay & GOES-2 & GOES-2 & 64.4 & 53 & 299 \\
\hline
\end{tabular}

\section{Data and method of analysis}

Hourly values of TEC obtained from VHF telemetry transmissions from geo-stationary satellites at the low-latitude station of Hawaii, mid-latitude station of Boulder and the high-latitude station of Goosebay for the solar maximum (1981) and minimum (1985) years of solar cycle 21 together with the corresponding hourly $f_{o} \mathrm{~F} 2$ (F2-layer critical frequency) values obtained simultaneously using ionosondes from the above three stations form the database of the present study (World Data Center A, Boulder, CO, USA). The peak electron density $N m \mathrm{~F} 2$ for each hour is computed using the relation:

$N m \mathrm{~F} 2=1.24(f o \mathrm{~F} 2)^{2} \times 10^{10} \mathrm{el} . \mathrm{m}^{-3}$, where $f o \mathrm{~F} 2$ is in $\mathrm{MHz}$.

The slab thickness $\tau$, in $\mathrm{km}$, for each hour is computed from the formula:

$\tau=T E C / N m F 2$.

The satellites used and their sub-ionospheric co-ordinates are given in Table 1 . In the present study, days with $A_{p} \leq 10 \mathrm{nT}$ are taken as magnetically quiet. The months of January, February, November, December; March, April, September, October; and May, June, July, August are respectively taken as winter, equinox and summer season. The daytime slab thickness is averaged for 08:00 to 16:00 LT and night-time slab thickness is averaged for 20:00 to 04:00 LT.

\section{Diurnal/seasonal/geomagnetic activity variations of slab thickness}

Figure 1 presents TEC, $f_{o} \mathrm{~F} 2$ and $\tau$ for five magnetically disturbed days (4 to 8 March 1981) and five quiet days (20 to 24 March 1981) at Goosebay. While both TEC and foF2 have been reduced during the magnetic storm on 5-6 March the increased slab thickness shows re-distribution of ionization towards the greater heights range during the storm. Increase of slab thickness is observed also during the day of 7 March when TEC is increased but $f o \mathrm{~F} 2$ is decreased. Thus the slab thickness behavior presents complementary characteristics of the ionosphere during the storm.

Figure 2a represents the mean diurnal variations of the slab thickness for the three seasons of winter, equinox and summer during solar minimum year 1985 for the low-, mid- and high-latitude stations. The crosses represent the mean variations for magnetically quiet days $\left(A_{p} \leq 10 \mathrm{nT}\right)$ alone and the continuous curves represent these for all days taken together (i.e. including disturbed days in the computation). The dayto-day fluctuations are smoothed out in the mean curves.

The seasonal variation of $\tau$ during solar minimum is generally characterised by pre-sunrise peak during the three seasons for the three latitudes. The night-time values of $\tau$ are higher compared to the daytime values during the different seasons in the three latitudes except during the summer season of low and high-latitude stations, where the reverse seems to be true. It is interesting to note that there is a steep fall in the slab thickness after sunset hours during solar minimum summer which is more conspicuous in the mid-latitude station. The effect of magnetic disturbance in the mean seasonal values for the low and high-latitudes is not significant. However, for the mid-latitude station of Boulder, the magnetic disturbance enhances the mean $\tau$ values during daytime as well night-time. The results from the present study for the low-latitude station are in agreement with other investigations mentioned in the Introduction.

Figure $2 b$ represents the mean diurnal variation of the slab thickness for the three seasons of winter, equinox and summer during solar maximum year 1981 for the low-, mid- and high-latitude stations. It is clear from Fig. $2 b$ that the solar phase change has significant influence on the $\tau$ variations in the three latitudes, particularly for the mid and high-latitudes. In contrast to the observations during solar minimum, the daytime values of $\tau$ at non-auroral latitudes are generally higher compared to the corresponding night-time values in different seasons during the solar maximum phase. The presunrise and pre-midnight peaks of $\tau$, which are generally observed for the three seasons of the solar minimum for the three latitudes, are preserved for high and low-latitudes during the solar maximum but not evident for the middle latitude. Though the magnetic activity does not have any significant influence on the $\tau$ variations at low- and mid-latitudes, it definitely enhances $\tau$ values during the three seasons of the solar maximum for the high-latitude during both daytime and night-time.

Table 2 gives the mean daytime (08:00-16:00 LT) and night-time (20:00-04:00 LT) values of ionospheric slab thickness for magnetically quiet days during the solar minimum phase (1985) and solar maximum (1981), for the stations of Hawaii, Boulder and Goosebay. From Table 2, it 

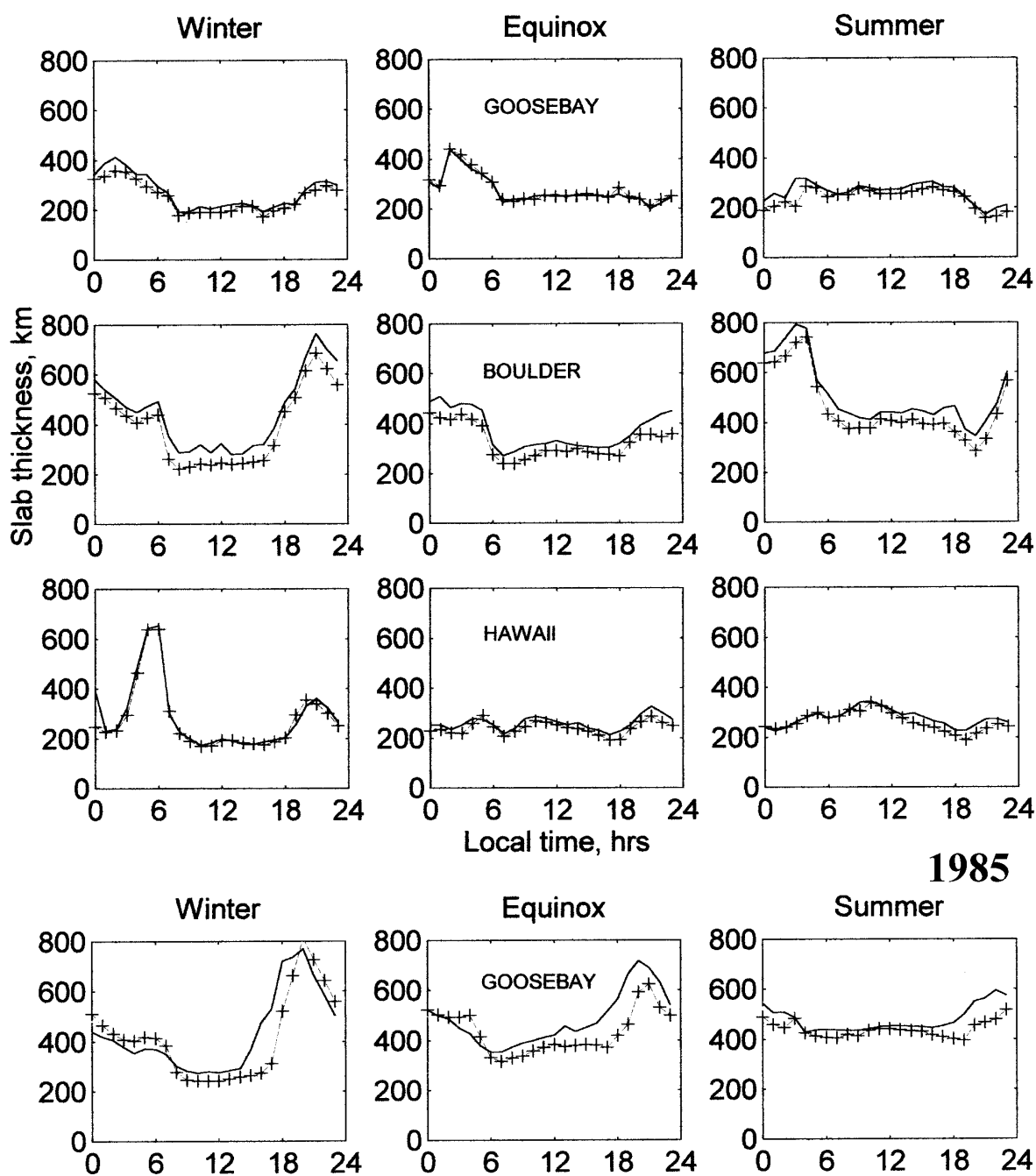

1985 (a)
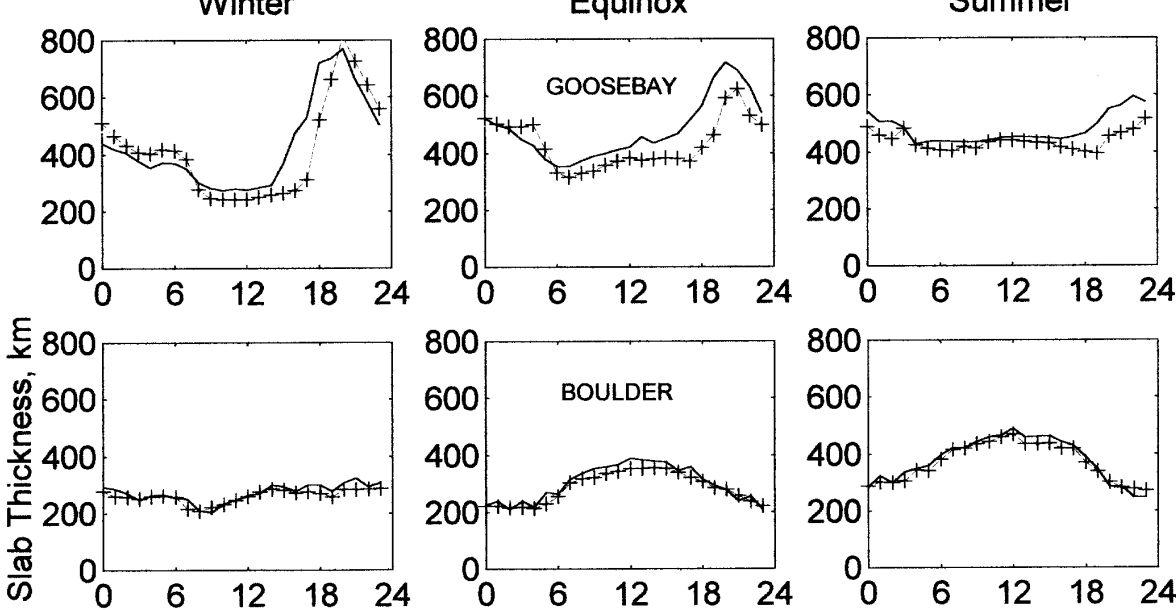

Summer
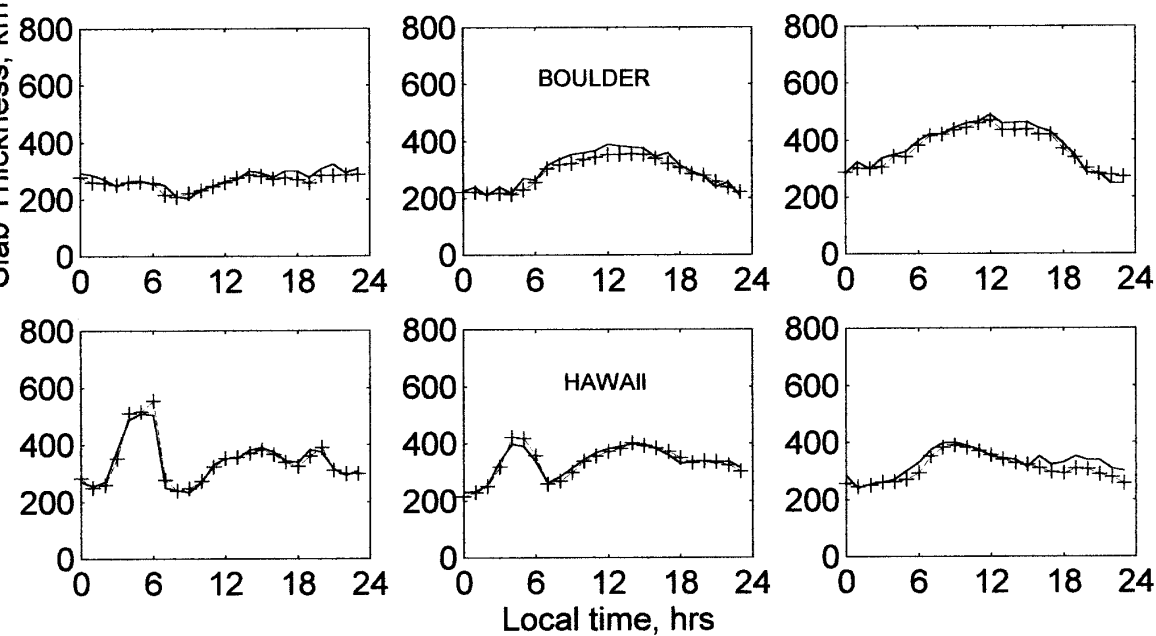

1981 (b)

Fig. 2. Seasonal variations of slab thickness for Hawaii, Boulder and Goosebay during (a) solar minimum year 1985, and (b) solar maximum year 1981 (.x x quiet days, all days). 
Table 2. Mean daytime (08:00-16:00 LT) and night-time (20:00-04:00 LT) values of ionospheric slab thickness, in km, for magnetically quiet days during the solar maximum phase 1981 and the solar minimum phase 1985 for the stations of Hawaii, Boulder and Goosbay for three seasons (WNT - winter, EQN - equinox, SMR - summer) and annual mean (YEAR).

\begin{tabular}{|c|c|c|c|c|c|c|c|c|c|}
\hline \multirow[t]{3}{*}{ Station } & \multirow[t]{3}{*}{ Time sector } & \multicolumn{8}{|c|}{ Slab Thickness, km } \\
\hline & & \multicolumn{4}{|c|}{1981} & \multicolumn{3}{|c|}{1985} & \\
\hline & & WNT & EQN & SMR & YEAR & WNT & EQN & SMR & YEAR \\
\hline \multirow[t]{2}{*}{ Hawaii } & Day & 323 & 355 & 354 & 344 & 187 & 241 & 288 & 239 \\
\hline & Night & 327 & 304 & 267 & 299 & 301 & 247 & 245 & 264 \\
\hline \multirow[t]{2}{*}{ Boulder } & Day & 253 & 342 & 439 & 345 & 240 & 278 & 394 & 304 \\
\hline & Night & 272 & 232 & 297 & 267 & 535 & 394 & 559 & 496 \\
\hline \multirow[t]{2}{*}{ Goosebay } & Day & 256 & 364 & 433 & 351 & 192 & 248 & 265 & 235 \\
\hline & Night & 527 & 528 & 488 & 514 & 313 & 309 & 201 & 274 \\
\hline
\end{tabular}

Table 3. Diurnal ratio and night/day (N/D) ratio of slab thickness for Hawaii, Boulder and Goosebay during the winter, equinox and summer seasons of the solar maximum year 1981 and solar minimum year 1985 .

\begin{tabular}{ccccccc}
\hline Diurnal Ratio & \multicolumn{3}{c}{1981} & & \multicolumn{3}{c}{1985} \\
& W & $\mathrm{E}$ & $\mathrm{S}$ & $\mathrm{W}$ & $\mathrm{E}$ & $\mathrm{S}$ \\
\hline Hawaii & 2.22 & 1.68 & 1.53 & 3.75 & 1.52 & 1.76 \\
N/D & 1.01 & 0.86 & 075 & 1.61 & 1.02 & 0.85 \\
Boulder & 1.38 & 1.72 & 1.8 & 3.09 & 1.82 & 2.55 \\
N/D & 1.07 & 0.68 & 0.68 & 2.23 & 1.42 & 1.42 \\
Goosebay & 2.99 & 2.04 & 1.31 & 2.27 & 2.09 & 1.77 \\
N/D & 2.06 & 1.45 & 1.13 & 1.63 & 1.25 & 0.76 \\
\hline
\end{tabular}

is found that, for magnetically quiet days at solar minimum, the mean night-time values are higher than the mean daytime values for the three seasons for low-, mid- and high-latitudes except during the summer of low- and high-latitudes where the reverse is the case. The mean daytime values of $\tau$ are highest in summer and lowest in winter for all three latitudes. Considering the night-time mean $\tau$ values, the reverse seems to be the case for low- and high-latitudes with nearly equal values of $\tau$ during the winter and summer seasons for the mid-latitude station where the lowest mean value is registered during the equinox. Mid-latitude mean $\tau$ values for both daytime and night-time are higher compared to corresponding low- and high-latitude values for the three seasons. Also, the difference between the mean daytime and nighttime values of $\tau$ is the highest for the mid-latitude during the three seasons. During the solar maximum phase, for magnetically quiet days the night-time mean values of $\tau$ are lower compared to the corresponding daytime values of the respective seasons for non-auroral latitudes. However, the winter night-time mean $\tau$ value for the mid-latitude station at Boulder is somewhat higher compared to the daytime mean value.

Thus, it is found that, while the night-time mean values of $\tau$ are generally higher compared to the daytime mean values in the different seasons for the three latitudes during the solar minimum, the reverse seems to be the case during solar max- imum at low- and mid-latitudes. For the high-latitude station at Goosebay the night-time values remain dominant. This is more evident from the annual mean values of slab thickness where the seasonal effects are smoothed out. For both solar phases the highest and lowest daytime mean $\tau$ values are registered, respectively, in summer and winter for the three latitudes.

Table 3 gives the diurnal ratios (maximum/minimum) of the slab thickness and also ratios of night-to-day mean values for Hawaii, Boulder and Goosebay during the winter, equinox and summer seasons of the solar maximum (1981) and solar minimum (1985) years. It is found that during the solar minimum the diurnal ratios are highest during the winter season for the three latitudes and these ratios are found to decrease with increase of latitude. During solar maximum, the diurnal ratios of the high-latitude station are higher compared to the corresponding values for the low- and midlatitudes during winter and equinox. The seasonal variation of the diurnal ratios is also greater for the high-latitude station. As distinct from the diurnal ratios which, by definition, are always greater than 1 , the night-to-day ratios are found to vary from 0.68 (Boulder, equinox and summer, solar maximum) to 2.23 (Boulder, winter, solar minimum). The difference between the two types of ratios is most effective for those conditions when the observed peak of slab thick- 



Fig. 3. Solar activity variation of slab thickness for Hawaii, Boulder and Goosebay during the winter season of solar maximum and minimum years.

ness refers to the sunrise/sunset hours when the ionosphere protonosphere plasma flux changes its direction.

\section{Solar activity variations}

In order to study the solar activity variations of the slab thickness, the mean daytime (08:00-16:00 LT) values of $\tau$ for magnetically quiet days are plotted against the corresponding $S_{10.7}$ solar flux values for the three latitudes during the three seasons of solar maximum and minimum phases.

Figure 3 gives the solar activity variation of daytime mean $\tau$ values during the winter season of the solar maximum and minimum phases for the three latitudes. It is clear from Fig. 3 that for the low-latitude station of Hawaii, the mean daytime $\tau$ values remain more or less constant for low solar flux values (below about 100 units of $S_{10.7}$ ) as well as high flux values (above about 170 units of $S_{10.7}$ ). However, the $\tau$ values are higher for the high solar flux values compared to the low solar flux values. The daytime mean $\tau$ value for the midlatitude in the winter season is somewhat lower compared to the low-latitude for low and high solar activity regions except for very low solar flux values below about 75 units of $S_{10.7}$ where $\tau$ values are higher compared to those for low-latitude. Thus the mid-latitude $\tau$ variation in winter is characterized by a decreasing trend in $\tau$ values with increase of solar flux in the low solar flux region. For high solar flux values the variation of $\tau$ with solar flux seems to be similar to that of the low-latitude. Considering the solar activity variation of the mean daytime values of $\tau$ for the high-latitude in winter, the $\tau$ values remain more or less constant with values somewhat higher compared to the low-latitude for low solar flux values. However, there is a linear increase of $\tau$ with solar flux values in the high solar activity level.

Variation of the daytime mean $\tau$ with solar activity during the equinox and summer seasons are very similar to the variation during winter but the magnitude of $\tau$ shows enhancements for the three latitudes during the solar maximum phase. In the low solar flux region, the daytime mean value of $\tau$ for the low- and high-latitudes remains more or less constant for the three seasons. However, the mid-latitude $\tau$ values decrease with solar activity for very low solar flux values below about 75 units of $S_{10.7}$ solar flux. During the solar 
Table 4. Mean daytime (08:00-16:00 LT) and night-time (20:00-04:00 LT) variability of ionospheric slab thickness for solar maximum year 1981 and solar minimum year 1985 for magnetically quiet days.

\begin{tabular}{llcccccc}
\hline Station & Time sector & & 1981 & & & 1985 & \\
& & WNT & EQN & SMR & WNT & EQN & SMR \\
\hline \multirow{2}{*}{ Hawaii } & Day & 15 & 12 & 17 & 26 & 18 & 19 \\
& Night & 45 & 37 & 30 & 39 & 34 & 30 \\
Boulder & Day & 10 & 10 & 17 & 14 & 13 & 34 \\
& Night & 32 & 21 & 29 & 24 & 40 & $\underline{67}$ \\
Goosbay & Day & 23 & 44 & 15 & 16 & 10 & 17 \\
& Night & 18 & 56 & 23 & 33 & 24 & 39 \\
\hline
\end{tabular}

maximum phase the variation of $\tau$ with solar activity shows a linear increase for the three seasons at the high-latitude station. Such a linear increase is evident only during the summer season for the mid-latitude and during the summer and equinox seasons for the low-latitude.

\section{Day-to-day variability}

The day-to-day variability of any parameter is best described by the ratio of the standard deviation to the monthly mean value. The mean seasonal values of such ratios of $\tau$, expressed as percentages $\left[\left(\sigma_{\text {mean }}\right) \times 100 \%\right]$, are given in Table 4 for the daytime (08:00-16:00 LT) and night-time (20:0004:00 LT) for solar maximum year (1981) and solar minimum year (1985) for magnetically quiet days.

For the solar minimum at low-latitude the mean $\tau$ variability is highest during winter for both daytime as well as night-time. For mid- and high-latitudes, the summer $\tau$ seems to be most variable for daytime as well as night-time. While the mean night-time $\tau$ variations are lowest during the summer, winter and equinox seasons respectively for low-, midand high-latitudes, the daytime of equinox shows the most stable behaviour of $\tau$ for the three latitudes.

During the solar maximum, for low-latitude, the summer daytime and winter night-time seem to be the most variable, whereas the equinox daytime and summer night-time are the most stable. Considering the mid-latitude, the variability in slab thickness is found to be the highest for summer daytime and winter night-time whereas the equinox seems to be most stable for both daytime and night-time. The equinox season at the high-latitude station seems to be the most variable of the different seasons for the three latitudes for both daytime and night-time.

\section{Discussion and conclusions}

The seasonal behaviour of slab thickness for an Indian lowlatitude station at Delhi $\left(26^{\circ} \mathrm{N}\right)$ during the ascending phase of the solar cycle 21 (1975 to 1980) has been discussed by Bhuyan et al. (1986). Their results are confirmed, more or less qualitatively, by our present study for the low-latitude station of Hawaii. Examining the decay trend in TEC and $N m \mathrm{~F} 2$ during the post midnight hours, they found a slump in TEC in winter around 04:00 to 05:00 LT while $N m \mathrm{~F} 2$ is still decaying causing an enhancement in $\tau$ during winter as observed in the present study. Also, the seasonal variation of $\tau$ presented in this study for the low-latitude station agrees qualitatively with their results. The yearly mean values of $\tau$ obtained in their study are $225 \mathrm{~km}$ and $400 \mathrm{~km}$, respectively, during the solar minimum and maximum phases. The corresponding values obtained in the present study are $240 \mathrm{~km}$ and $340 \mathrm{~km}$, respectively. According to Huang (1983) the seasonal dependence of the occurrence of presunrise and prenoon peaks and subsidiary peaks after sunset, observed in the slab thickness for the low-latitude station of Lumping $\left(25^{\circ} \mathrm{N}, 121.17^{\circ} \mathrm{E}\right)$, is associated with the solar activity variations. In the present study such very large presunrise winter night-time values of $\tau$ at low-latitude are observed for solar minimum and maximum while these disappear at solar maximum at mid-latitudes and move to the post-sunset hours at high latitute.

Many authors have reported positive dependence of slab thickness on $S_{10.7}$ solar flux from various locations (Bhonsle et al., 1965; Dabas et al., 1984; Tyagi and Somayajulu, 1966). Davies and Liu (1991) studied the slab thickness at 15 stations in the low- and mid-latitudes (1967-1986) and found its solar cycle dependence; they observed that the noontime slab thickness increases with increase of solar flux in all seasons. They concluded that the predawn increase in slab thickness is caused by low values of $N m \mathrm{~F} 2$, not by increase of TEC. However, while studying the variations of $\tau$ during the declining phase of the solar cycle 21 for the Chinese low-latitudes, Liu et al. (1992) report only a weak linear dependence of slab thickness with 12 months running mean sunspot number. The present study of solar activity dependence on $\tau$ indicates that it varies with latitude, season and also with the levels of solar activity. During solar maximum, in general, there is a linear increase of $\tau$ with solar flux for the different seasons of the three latitudes except during the winter season at low-latitude and during the winter and equinox seasons at mid-latitude. For low solar flux values, the slab thickness remains more or less constant for low and highlatitudes for the three seasons. However, for mid-latitude, it 
shows a decreasing trend with increasing solar flux for very low flux values. Buonsanto et al. (1979) made a comparative study of the variation of $\tau$ for the mid-latitude station at Sagamore Hill and the high-latitude station at Goosebay during the low, medium and high solar activity periods of the 20 solar cycle. They could observe many similarities in the variations of $\tau$ for both locations. Our results indicate that night-time-to-daytime ratio of $\tau$ at solar minimum/maximum differs at high-latitudes from the low and mid-latitudes.

Most of the earlier studies of the influence of geomagnetic activity on the slab thickness were inconclusive. Bhuyan et al. (1986) report no correlation between slab thickness and magnetic activity index $A_{p}$ for Indian low-latitudes and the results from the present study for the low-latitude station of Hawaii agree well with their results. Chauhan and Gurm (1981) report, from their study during the solar minimum period of 1975-76 for Indian low-latitudes, that increase and decrease of slab thickness occurs with equal frequency and concluded that magnetic activity has no definite impact on slab thickness. Kersley and HajebHossinieh (1976) report a positive correlation between $\tau$ and magnetic activity during medium solar activity conditions for the mid-latitude station of Aberystwith $\left(53^{\circ} \mathrm{N}, 4^{\circ} \mathrm{W}\right)$. The variation of $\tau$ during storm times are thought to be brought about by the competing effects of (1) electric fields and winds which tend to raise the layer (and lower the loss rate) in the early phase of the storm, (2) increase in the scale height of the neutral atmosphere caused by the heat deposited in the auroral zone and (3) changes in the composition of the atmosphere brought about by the redistribution of the lighter constituents (e.g. He and $\mathrm{O}$ ) as a result of the winds established by auroral heating. Additional effects such as heating by the thermal conduction from the magnetosphere and from the precipitation of low energy electrons are important only during night-time. All these effects vary from storm to storm and their importance depends considerably on the location of the observing stations and also on the levels of solar activity. However, the work of Yeh and Flaherty (1966) reveals a positive correlation between slab thickness and $K_{p}$ index for temporal latitudes.

The present study indicates a positive dependence of slab thickness on magnetic activity for mid-latitude during solar minimum and for high-latitude during solar maximum. It has been reported that the compression of the magnetosphere during a geomagnetic storm could lead to a positive ionospheric response at mid-latitudes. From simultaneous TEC and magnetic field measurements Mendillo et al. (1970) suggested that magnetospheric compression caused an enhancement in TEC at mid-latitudes. A decrease in plasmaspheric content following an increase in ionospheric content during geomagnetic storms has also been observed by Kersley and Klobuchar (1980). This could explain the observed increase in slab thickness due to magnetic activity at mid-latitudes at solar minimum. During solar maximum, for the auroral station Goose Bay, several structured positive phases have been reported during disturbed conditions and might be attributed to auroral particle precipitation (Yeh et al., 1994). This may be the reason for the enhanced slab thickness due to magnetic disturbance observed here for the high-latitude station during solar maximum.

Another important feature of the slab thickness presented in this study is its large day-to-day variability. $\tau$ being the ratio of TEC to $N m \mathrm{~F} 2$, the day-to-day variability of $\tau$ must reflect the combined effect of the variabilities of both the parameters simultaneously. Bhuyan et al. (1986) report, from low-latitudes that the day-to-day variability in $\tau$ occurs in the form of single day abnormalities, alternate day-to-day fluctuations and long term periodicities of one month or more; they also found that on a particular day $\tau$ varies by $30-50 \%$ from the previous day's values. Variations as large as $100 \%$ have been noticed on several occasions. Our results show, for solar minimum, percentage standard deviation changes from $10 \%$ by day (equinox, high-latitude) to $67 \%$ by night (summer, mid-latitude) and, for solar maximum, from $10 \%$ by day (winter and equinox, mid-latitude) to $56 \%$ by night (equinox, high-latitude).

The present study on the variations of the ionospheric slab thickness at low-, mid- and high-latitudes during the strong solar cycle 21 brings out the following important results:

1. The diurnal variations of $\tau$, during the different seasons of solar minimum for the non-auroral latitudes, are generally characterised by higher night-time values compared to the daytime values; the reverse is true during solar maximum. However, night-time $\tau$ values are dominant at the Goosebay auroral station for solar minimum and maximum phases. This difference in the behavior of $\tau$ at high-latitudes can be consequence of plasma diffusion along open field lines because the field aligned plasma exchange between the protonosphere and ionosphere at non-auroral latitudes keeps the ionosphere thicker during the daytime than at night at solar maximum.

2. Magnetic disturbance seems to enhance the $\tau$ values for mid-latitude during solar minimum and for highlatitude during solar maximum. The night-time dayto-day variability of slab thickness is higher compared to the daytime variability during the three seasons for both solar phases for the low-, mid- and high-latitude stations.

Acknowledgements. The authors are grateful to J. W. Wright and one unknown referee for helpful comments and suggestions.

Topical Editor M. Lester thanks J. W. Wright and N. Balan for their help in evaluating this paper.

\section{References}

Balan, N. and Bailey, G. J.: Equatorial plasma fountain and its effects: Possibility of additional layer, J. Geophys. Res., 100, $21421,1995$.

Bhonsle, R. V., Da Rosa, A. V., and Garriott, O. K.: Measurement of Total Electron Content and the Equivalent Slab Thickness of the Mid latitude Ionosphere, Radio Science, 69D, 7, 929, 1965. 
Bhuyan, P. K., Lakha Singh, and Tyagi, T. R.: Equivalent slab thickness of the ionosphere over $26^{\circ} \mathrm{N}$ through the ascending half of a solar cycle, Ann. Geophysicae, 4, 131, 1986.

Bhuyan, P. K. and Tyagi, T. R.: Annual and semiannual periodicities in IEC at low-latitudes, Indian J. Radio Space Phys., 14, 61, 1985.

Buonsanto, M. J., Mendillo, M., and Klobuchar, J. A.: The Ionosphere at $L=4$ : Average behaviour and the response to geomagnetic storms, Ann. Geophysicae, 35, 15, 1979.

Chauhan, N. S. and Gurm, H. S.: Storm time slab thickness at lowlatitudes, Ann. Geophysicae, 32,2, 287, 1981.

Dabas, R. S., Bhuyan, P. K., Tyagi, T. R., Bharadwaj, P. K., and Lal, J. B.: Day-to-day changes in ionospheric electron content at low-latitudes, Radio Sci., 19, 749, 1984.

Davies, K., Fritz, R. B., and Gray, T. B.: Measurement of columnar electron contents of the ionosphere and plasmasphere, J. Geophys. Res., 81, 2825, 1976.

Davies, K. and Liu, X. M.: Ionospheric slab thickness in middle and low-latitudes, Radio Sci., 26, 1997, 1991.

Essex, E. A.: Ionospheric total electron content at Southern midlatitude during 1971-1974, J. Atmos. Terr. Phys., 40, 1019, 1978.

Evans, J. V. and Holt, J. M.: Night time proton flux at Millstone Hill, Planet. Space Sci., 26, 727, 1978.

Furman, D. R. and Prasad, S. S.: Ionospheric slab thickness; its relation to temperature and dynamics, J. Geophys. Res., 78, 5837, 1973.

Gulyaeva, T. L.: TEC residual slab thickness between bottomside and topside ionosphere, Acta. Geod. Geoph. Hung., 32, 355, 1997.

Huang, Y. N.: Some result of Ionospheric slab thickness observations at Lunping, J. Geophys. Res., 88, 5517, 1983.

Kersley, L. and Hajeb Hosseinieh. H.: Dependence of Ionospheric slab thickness on geomagnetic activity, J. Atmos.Terr. Phys., 38, 1357, 1976.

Kersley, L. and Klobuchar, J. A.: Storm associated protonospheric depletion and recovery, Planet. Space Sci., 28, 453, 1980.

Liu, Xuanmou, Liu, Hong, and Chang, M.: Behavior of the ionospheric slab thickness over Chinese mid-latitude region for half solar cycle, Proc. URSI, IBSS, Cambridge, M.A., USA, p. 200, 1992.
Mc Namara, L. F. and Smith, D. H.: TEC of the ionosphere at 310 S, 1967-1974, J. Atmos. Terr. Phys., 44, 227, 1982.

Mendillo, M., Papagiannis, M. D., and Klobuchar, J. A.: Ionospheric storms at midlatitudes, Radio Sci., 5, 895, 1970.

Minakoshi, H. and Nishimuta, I.: Ionospheric electron content and equivalent slab thickness at lower mid-latitudes in the Japanese zone, Proc. IBSS, University of Wales, U.K., 144, 1994.

Modi, R. P. and Iyer, K. N.: Ionospheric electron content and slab thickness near the peak of equatorial anomaly during sunspot maximum and minimum, Indian J. Radio Space Phys., 18, 23, 1989.

Noxon, J. F. and Johanson, A. E.: Effect of magnetically conjugate photo electrons on OI (6300A), Planet. Space Sci, 18, 1367, 1970.

Rao. P. B., Jayachandran, B., and Balan, N.: Low latitude TEC and Np variations during the solar cycles of 20 and 21, in: Investigation of ionosphere by means of Beacon satellite measurements, edited by Cao Chong, Int. Beacon Satellite symposium, Beijing, China, p. 241, 1988.

Rastogi, R. G.: Collapse of the equatorial ionosphere during the sunrise period, Ann. Geophysicae, 6, 205, 1988.

Titheridge, J. E.: The slab thickness of the mid-latitude ionosphere, Planet. Space Sci., 21, 1775, 1973.

Tyagi, T. R. and Somayajulu, Y. V.: Some results of electron content measurements at Delhi from Faraday fading of S-66 transmissions, Radio Sci., 1, 1125, 1966.

Walker, G. O. and Ting, S. D.: Electron content and other related measurements for a low-latitude station obtained at sunspot maximum using geostationary satellite, J. Atmos. Terr. Phys., 34, 283, 1972.

Wright, J. W.: A model of the F-region above $h_{\max } \mathrm{F} 2$, J. Geophys. Res., 65, 185, 1960.

Yeh, K. C. and Faherty, B. J.: Ionospheric Electron Content at temperate latitudes during the declining phase of the sunspot cycle, J. Geophys. Res., 71, 4557, 1966.

Yeh, K. C., Ma, S. Y., and Lin, K. H.: Global ionospheric effects of the October 1989 geomagnetic storm, J. Geophys. Res., 99, 6201, 1994. 